\title{
Prognostic value of long-term trajectories of depression for incident diabetes mellitus in patients with stable coronary heart disease
}

\author{
Raphael S. Peter ${ }^{1 *}$ (D), Andrea Jaensch ${ }^{1}$, Ute Mons ${ }^{2,3}$, Ben Schöttker ${ }^{2,4}$, Roman Schmucker ${ }^{5}$, Wolfgang Koenig ${ }^{1,6,7}$,
} Hermann Brenner, ${ }^{2,4}$ and Dietrich Rothenbacher ${ }^{1,2}$

\begin{abstract}
Background: Diabetes mellitus (DM) and depression are bidirectionally interrelated. We recently identified long-term trajectories of depression symptom severity in individuals with coronary heart disease (CHD), which were associated with the risk for subsequent cardiovascular events (CVE). We now investigated the prognostic value of these trajectories of symptoms of depression with the risk of incident DM in patients with stable coronary heart disease.

Methods: The KAROLA cohort included CHD patients participating in an in-patient rehabilitation program (years 1999/2000) and followed for up to 15 years. We included 1048 patients (mean age 59.4 years, 15\% female) with information on prevalent DM at baseline and follow-up data. Cox proportional hazards models were used to model the risk for incident DM during follow-up by depression trajectory class adjusted for age, sex, education, smoking status, body mass index, and physical activity. In addition, we modeled the excess risk for subsequent CVE due to incident DM during follow-up for each of the depression trajectories.
\end{abstract}

Results: DM was prevalent in 20.7\% of patients at baseline. Over follow-up, 296 (28.2\%) of patients had a subsequent CVE. During follow-up, 157 (15.0\%) patients developed incident DM before experiencing a subsequent CVE. Patients following a high-stable depression symptom trajectory were at substantially higher risk of developing incident DM than patients following a low-stable depression symptom trajectory (hazard ratio $(\mathrm{HR})=2.50 ; 95 \%$ confidence interval (Cl) $(1.35,4.65))$. A moderate-stable and an increasing depression trajectory were associated with HRs of $1.48(95 \%-\mathrm{Cl}$ $(1.10,1.98))$ and $1.77(95 \%-\mathrm{Cl}(1.00,3.15))$ for incident DM. In addition, patients in the high-stable depression trajectory class who developed incident DM during follow-up were at 6.5-fold risk ( $\mathrm{HR}=6.51$; 95\%-Cl $(2.77,15.3))$ of experiencing a subsequent cardiovascular event.

Conclusions: In patients with CHD, following a trajectory of highstable symptoms of depression was associated with an increased risk of incidentDM. Furthermore, incident DM in these patients was associated with asubstantially increased risk of subsequent CVE. Identifying depressive symptomsand pertinent treatment offers might be an important and promising approach toenhance outcomes in patients with CHD, which should be followed up in furtherresearch and practice.

Keywords: Depression, Trajectories, Diabetes mellitus, Coronary heart disease

*Correspondence: raphael.peter@uni-ulm.de

${ }^{1}$ Institute of Epidemiology and Medical Biometry, Ulm University, Ulm, Germany

Full list of author information is available at the end of the article

\section{Background}

Diabetes mellitus (DM) is a global public health problem that increases strongly in all parts of the world [1]. Diabetes mellitus and depression are bidirectionally

c) The Author(s) 2021. This article is licensed under a Creative Commons Attribution 4.0 International License, which permits use, sharing, adaptation, distribution and reproduction in any medium or format, as long as you give appropriate credit to the original author(s) and the source, provide a link to the Creative Commons licence, and indicate if changes were made. The images or other third party material in this article are included in the article's Creative Commons licence, unless indicated otherwise in a credit line to the material. If material is not included in the article's Creative Commons licence and your intended use is not permitted by statutory regulation or exceeds the permitted use, you will need to obtain permission directly from the copyright holder. To view a copy of this licence, visit http://creativeco mmons.org/licenses/by/4.0/. The Creative Commons Public Domain Dedication waiver (http://creativecommons.org/publicdomain/ zero/1.0/) applies to the data made available in this article, unless otherwise stated in a credit line to the data. 
interrelated [2]. On the one hand, there is an increased risk of depression in patients with prevalent DM [3]. On the other hand, individuals diagnosed with depression or depressive symptoms are at increased risk of incident DM [4].

Among patients with DM, depression has been associated with a higher prevalence of microvascular and macrovascular complications [5-7]. In addition, symptoms of depression have been associated with poorer adherence to cardio-metabolic therapies in DM patients [8].

In addition, coronary heart disease (CHD) is still the leading cause of morbidity and mortality worldwide [9]. DM and CHD share common risk factors and some pathogenic pathways like chronic low-grade inflammation [10], a well-established marker in CHD pathology. As indicated by the serum level of C-reactive protein (CRP), systemic vascular inflammation may play multiple roles in the progression and destabilization of CHD and is also relevant in patients with already existing CHD [11]. Lowgrade systemic inflammation seems to play also a role in the pathophysiology of depression [12].

We recently identified long-term trajectories of depression symptom severity in patients with coronary heart disease during long-term follow-up (CHD) [13], namely a low-stable, a moderate-stable, an increasing, and a highstable trajectory class. The high stable depression class comprising about $3.3 \%$ of patients was associated with a substantially increased risk (hazard ratio $=2.47$ ) of subsequent fatal or non-fatal cardiovascular events (CVE).

As there is evidence that depression is a risk factor for $\mathrm{DM}$, trajectories of symptoms of depression may also be associated with incident DM during follow-up of CHD patients, and incident DM might again further increase the risk of subsequent CVE. However, results are inconsistent yet but might have important implications for provisions and timing of secondary prevention measures during in-patient rehabilitation and for long-term outpatient care, but also for further understanding of shared disease pathways of CHD and diabetes. To our knowledge, long-term trajectories of symptoms of depression in relation to DM in patients with CHD have not been investigated so far.

In this study, we investigated the prognostic value of long-term trajectories of symptoms of depression on the occurrence of incident DM in patients with CHD and the excess risk for subsequent CVE due to DM in patients following these different depression trajectories.

\section{Methods}

\section{Subjects}

The prospective KAROLA cohort study included patients with CHD (International Classification of Diseases (ICD), 9th Rev. pos. 410-414) aged 30-70 years participating in an in-patient rehabilitation program between January 1999 and May 2000 in one of two rehabilitation clinics in Germany (Schwabenland-Klinik, Isny, and Klinik am Südpark, Bad Nauheim), as previously described [13, 14]. In Germany, all patients discharged from an acute care hospital after an acute coronary syndrome or coronary artery bypass grafting are offered a comprehensive inhospital rehabilitation program (on average about three weeks long). KAROLA only included patients admitted to in-patient rehabilitation within 3 months after their first acute event or coronary artery bypass grafting treated in an acute care hospital. Of all eligible patients admitted to the in-patient rehabilitation clinic during the recruitment period, $58 \%(\mathrm{n}=1206)$ agreed to participate.

\section{Assessment of symptoms of depression and trajectory class membership}

The German version [15] of the hospital anxiety and depression scale (HADS) was included in questionnaires at the 1-, 3-, 6-, 8-, and 15-year follow-up. HADS is a standardized, self-administered questionnaire containing 14 questions to quantify generalized anxiety and depression (seven items each) in medical patients [16] and performs well in patients with cardiac diseases. All items are scored on a four-point Likert scale ( $0-3$ points). A summary score is calculated for the depression subscale ranging from 0 to 21 . Only the depression subscale of the HADS is included in the present analysis.

We previously identified four long-term trajectories of depression symptoms within the KAROLA study population using a joint latent class mixture time-to-event model [13]. Based on this model, trajectory class membership probabilities were assigned to each individual in the current analysis dataset.

\section{Follow-up and evaluation of cardiovascular disease events and diabetes mellitus}

Up to the 15-year follow-up (ending in May 2015), each patient and the actual primary care physicians were contacted regularly (at 1, 3, 6, 8, 10, 13 and 15 years) by mail and asked to complete standardized questionnaires regarding comorbidity, subsequent non-fatal CVEs, and medication and treatment since discharge from the inpatient rehabilitation clinic. The vital status during follow-up was assessed via the residents' registration office. In case of death, the exact date and location of death were obtained, and the death certificate was obtained from the local Public Health department. The main cause of death was coded according to the International Classification of Diseases. A subsequent CVE was defined as cardiovascular disease (CVD) as the main cause of death (ICD-9 pos. 390-459; ICD-10 pos. I0-I99 and R57.0) or a primary care physician reporting a non-fatal myocardial 
infarction or stroke. Incident DM was defined as a primary care physician reporting a new DM diagnosis for the first time. Prevalent diabetes at baseline included DM reported by the primary care physician, by the patient or the patient reporting intake of antidiabetic medication.

\section{Statistical methods}

Characteristics by previously identified depression symptom trajectories are presented as means and standard deviations weighted by class membership probabilities for continuous variables and as frequencies weighted by class membership probabilities for discrete variables.

The hazard ratios (HR) for incident diabetes by trajectory class were modeled as a Cox proportional hazards model with time since hospital admission as the underlying timescale. Time at risk started at discharge from the in-patient rehabilitation clinic (left truncation) and ended when reaching the DM endpoint. Time at risk was censored when the patient was lost to follow-up, the patient died, experienced a subsequent CVE, or reached the last (15-year) follow-up. Models were fitted on an extended dataset (one row per individual and trajectory class) and weighted by trajectory class membership probability. The HRs for the excess CVE risk due to DM were modeled using Cox models with DM as a time-varying exposure. We used the same timescale as for the previous models but with subsequent CVE as the endpoint, again on an extended dataset weighted by class trajectory membership probability. The models included a trajectory-classmembership (as strata) by DM interaction term.

We used two different adjustment sets, one including age and sex, and one additionally adjusted for education ( $<10$ years vs. $\geq 10$ years), smoking status (former/current smoker vs. never smoker), body mass index (BMI), and physical activity (up to $3 \mathrm{~h}$ of sweaty activity per week, more than $3 \mathrm{~h}$ per week, or not answered). When incident DM was analysed, patients with prevalent DM at baseline were excluded. All confidence intervals for HRs were derived using the model-based robust variance estimates. All analyses were performed with R ( $\mathrm{R}$ Foundation for Statistical Computing, Vienna, Austria) version 3.6.3.

\section{Results}

Information on depression trajectories and DM was available for 1048 patients out of 1206 individuals who agreed to participate (Fig. 1).

These patients were on average 59.4 years old at study inclusion, only $15 \%$ of patients were female, and $20.7 \%$ already had prevalent DM at baseline (Table 1). Over 15 years of follow-up, 296 (28.2\%) of patients had a subsequent CVE, 157 (15.0\%) of the total study population developed incident DM before experiencing a

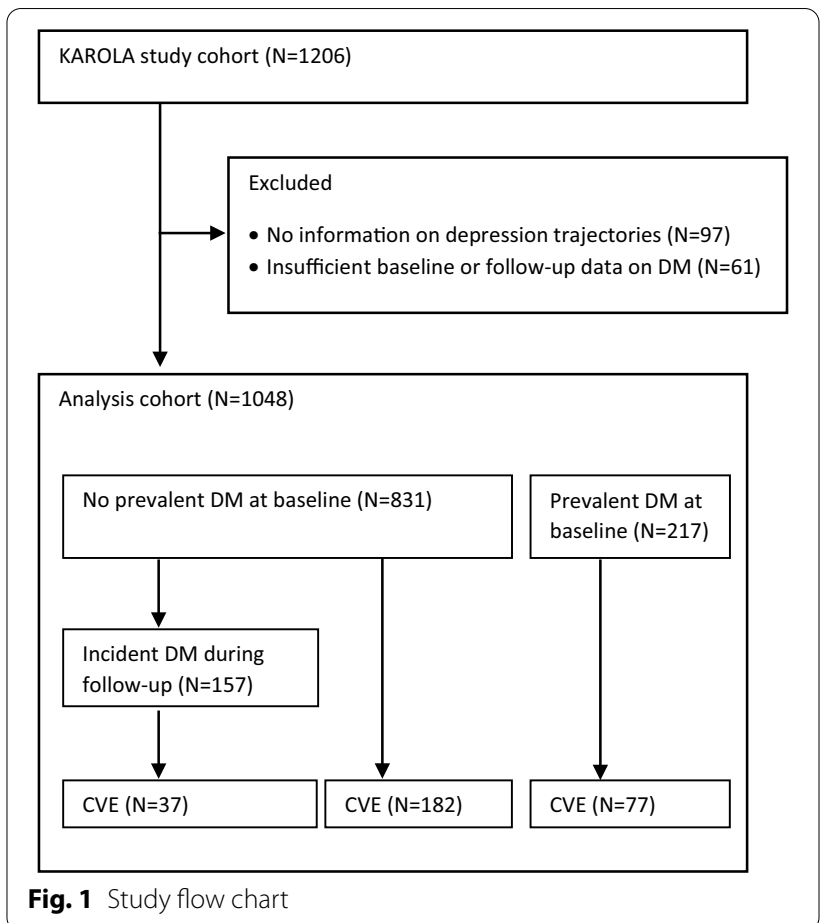

subsequent CVE, leading to an incidence rate of 17.2 per 1000 patient-years.

The previously identified depression trajectories of this cohort are shown in Fig. 2. Patients with a high probability of belonging to the high stable depression trajectory were more likely to have prevalent DM already at baseline (Table 2) (30.1\% for the high-stable class vs. $19.1 \%$ for the low-stable class). Also, subsequent CVEs were much more common in the high-stable class $(47.4 \%$ vs. $26.3 \%$ for the low-stable class), as was incident DM (21.9\% vs. $13.5 \%$ for the low-stable class).

The risk for incident DM was 2.83 times as high for the high-stable depression class as for the low-stable trajectory (Table 3), after adjustment for age and sex. Also, individuals following the moderate-stable and increasing depression trajectories faced a substantially increased risk (HRs of 1.55 and 2.50) for incident DM. Further adjustment for education, smoking status, BMI, and physical activity only slightly attenuated the HRs.

Table 4 displays excess cardiovascular event (CVE) risk due to prevalent diabetes mellitus (DM) at baseline and incident DM during follow-up. When looking on the risk estimates of subsequent CVEs by DM prevalence at baseline vs. no prevalent DM, we found an increased risk for the low-stable, moderate-stable, and high-stable depression trajectory class. However, confidence intervals were wide and mostly included the null effect value. Interestingly, patients who fell into the 
Table 1 Main characteristics of the study population (all characteristics refer to baseline, except incidence figures)

\begin{tabular}{|c|c|}
\hline & $N=1048$ \\
\hline Age (years), mean (SD) & $59.4(8.0)$ \\
\hline Female sex, $n(\%)$ & $157(15.0)$ \\
\hline Education $<10$ years, $n(\%)$ & $627(59.8)$ \\
\hline Former/current smoker, n (\%) & 709 (67.6) \\
\hline Body mass index $\left(\mathrm{kg} / \mathrm{m}^{2}\right)$, mean (SD) & $26.9(3.3)$ \\
\hline \multicolumn{2}{|l|}{ Physical activity, $\mathrm{n}(\%)^{\mathrm{a}}$} \\
\hline Up to 3 h per week & $477(45.5)$ \\
\hline More than $3 \mathrm{~h}$ per week & $544(51.9)$ \\
\hline Not answered & $27(2.6)$ \\
\hline History of myocardial infarction, n (\%) & $604(57.6)$ \\
\hline Prevalent diabetes mellitus, $\mathrm{n}(\%)$ & $217(20.7)$ \\
\hline \multicolumn{2}{|l|}{ Clinical score (angiographic evaluation), n (\%) } \\
\hline 0 - or 1-vessel disease & $274(26.1)$ \\
\hline 2-vessel disease & $280(26.7)$ \\
\hline 3-vessel disease & $445(42.5)$ \\
\hline Unknown & $49(4.7)$ \\
\hline Subsequent cardiovascular (CV) events, N (\%) & $296(28.2)$ \\
\hline Incident diabetes (until subsequent CV event), N (\%) & $157(15.0)$ \\
\hline
\end{tabular}

a sweaty activities within the year prior to the index event

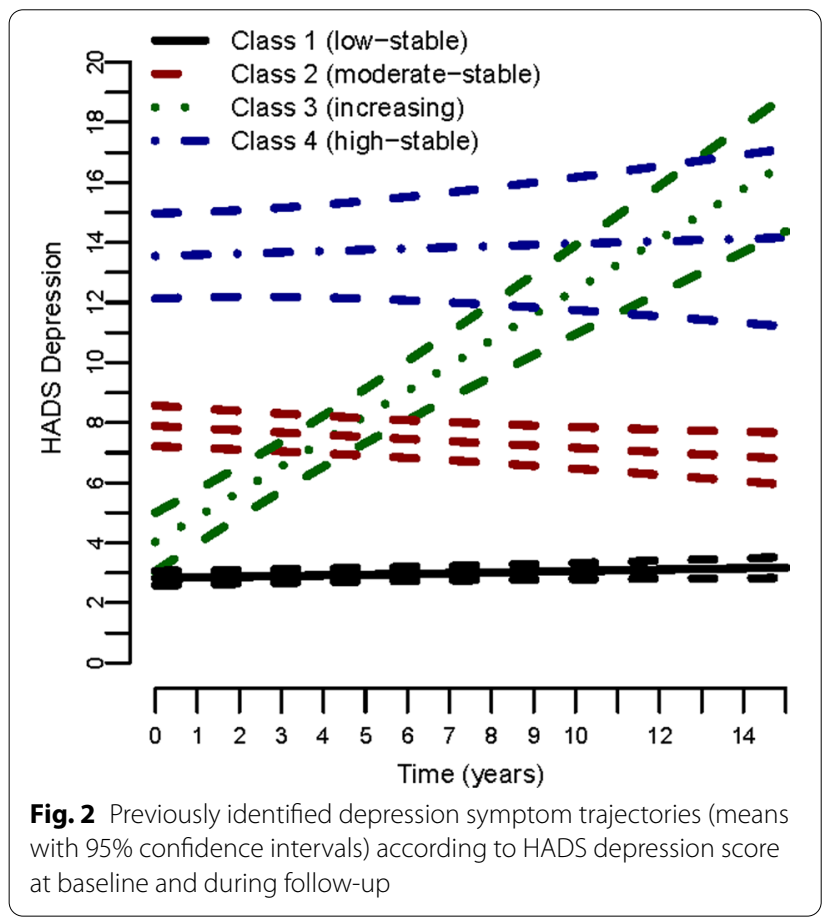

high-stable depression trajectory class and who developed incident DM during follow-up were at 6.5 -fold risk of experiencing a subsequent $\mathrm{CVE}$ compared to those in the same depression trajectory class who did not develop DM.

\section{Discussion}

In this long-term cohort study, including over 1000 patients with stable CHD at baseline, we found that patients on a trajectory of high stable depression symptoms during long-term follow-up faced an increased risk of developing DM. In addition, those following a trajectory of high-stable depression symptoms who newly developed DM faced a substantial 6.5-fold increased risk for subsequent CVEs. Therefore, more attention should be given to symptoms of depression both in the initial phase of diagnosis of CHD during in-patient rehabilitation and also during long-term care of CVD-patients. If the diagnosis is confirmed by a clinical examination (as HADS is basically a screening instrument), a respective treatment of depression should be initiated. In addition, given the increased risk for DM, the metabolic state should be watched carefully to allow early preventive means.

To our knowledge, long-term trajectories of symptoms of depression in relation to DM in patients with CHD have not been investigated so far. However, depressive symptoms have previously been shown to be associated with DM incidence [17], and depression has been consistently associated with a higher prevalence of macrovascular complications in patients with DM [5-7]. Notably, patients with DM requiring glucose-lowering 
Table 2 Characteristics by previously identified depression symptom trajectories

\begin{tabular}{|c|c|c|c|c|}
\hline & $\begin{array}{l}\text { Class } 1 \\
\text { (low-stable) }^{\mathrm{a}}\end{array}$ & $\begin{array}{l}\text { Class } 2 \\
\text { (moderate-stable) }^{\mathrm{a}}\end{array}$ & $\begin{array}{l}\text { Class } 3 \\
\text { (increasing) }^{\mathrm{a}}\end{array}$ & $\begin{array}{l}\text { Class } 4 \\
\text { (high-stable) }\end{array}$ \\
\hline N (\%) & $711.5(67.9)$ & $245.5(23.4)$ & $56.7(5.4)$ & $34.3(3.3)$ \\
\hline Age (years), mean (std) & $59.6(7.9)$ & $58.6(8.0)$ & $61.3(8.4)$ & $57.3(8.2)$ \\
\hline Female sex, N (\%) & $102.3(14.4)$ & $41.4(16.9)$ & $8.2(14.4)$ & $5.1(14.8)$ \\
\hline Prevalent diabetes mellitus at baseline (\%) & $163.2(19.1)$ & $57.0(23.2)$ & $13.5(23.7)$ & $10.3(30.1)$ \\
\hline Subsequent cardiovascular (CV) events, N (\%) & $187.2(26.3)$ & $67.9(27.7)$ & $24.6(43.4)$ & $16.3(47.4)$ \\
\hline $\begin{array}{l}\text { Incident diabetes (until subsequent CV event) } \\
\mathrm{N}(\%)\end{array}$ & $95.8(13.5)$ & $44.8(18.3)$ & $8.9(15.7)$ & 7.5 (21.9) \\
\hline
\end{tabular}

a Statistics (including Ns) are weighted by the probability of class membership; Ns might therefore be non-natural numbers

${ }^{b}$ Excluding patients with prevalent DM at baseline

Table 3 Hazard ratio for development of DM during follow-up by depression trajectory class $\left(\mathrm{N}_{\text {Total }}=831, \mathrm{~N}_{\text {Events }}=157\right)$

\begin{tabular}{lcccr}
\hline & $\mathbf{N}_{\text {Events }} \mathbf{c}$ & $\begin{array}{l}\text { Follow-up } \\
\text { (Person-years) }\end{array}$ & $\begin{array}{l}\text { Age- \& sex-adjusted } \\
\text { Hazard ratio } \\
(\mathbf{9 5 \% - C l )}\end{array}$ & $\begin{array}{l}\text { Fully adjusted } \\
\text { Hazard ratio } \\
\mathbf{( 9 5 \% - C l )}\end{array}$ \\
\hline Class 1 (low-stable) & 95.8 & 5911 & $($ ref.) 1.00 & $($ ref.) 1.00 \\
Class 2 (moderate-stable) & 44.8 & 1783 & $1.55(1.16,2.08)$ & $1.48(1.10,1.98)$ \\
Class 3 (increasing) & 8.9 & 317 & $1.94(1.10,3.44)$ & $1.77(1.00,3.15)$ \\
Class 4 (high-stable) & 7.5 & 181 & $2.83(1.53,5.23)$ & $2.50(1.35,4.65)$ \\
\hline
\end{tabular}

${ }^{a}$ Excluding patients with prevalent DM at baseline

b Adjusted for age, sex, education, smoking status, BMI, and physical activity

c Statistics are weighted by the probability of class membership; Ns might therefore be non-natural numbers

Table 4 Excess cardiovascular event (CVE) risk due to prevalent diabetes mellitus (DM) at baseline and incident DM during follow-up

\begin{tabular}{|c|c|c|c|}
\hline & \multicolumn{3}{|c|}{ Hazard ratio $(95 \%-\mathrm{Cl})$} \\
\hline & $\begin{array}{l}\text { Prevalent DM vs. } \\
\text { no prevalent } \mathrm{DM}^{\mathrm{a}}\end{array}$ & $\begin{array}{l}\text { Prevalent + incident DM } \\
\text { vs. no DM }\end{array}$ & $\begin{array}{l}\text { Incident DM } \\
\text { vs. no } \mathrm{DM}^{\mathrm{b}}\end{array}$ \\
\hline $\mathrm{N}_{\text {CVE }} / \mathrm{N}_{\text {Total }}$ & $296 / 1048$ & $296 / 1048$ & 219/831 \\
\hline \multicolumn{4}{|l|}{ Age- and sex-adjusted models } \\
\hline Class 1 (low-stable) & $1.40(1.03,1.90)$ & $1.39(1.05,1.85)$ & $1.31(0.82,2.11)$ \\
\hline Class 2 (moderate-stable) & $1.51(0.97,2.36)$ & $1.18(0.79,1.78)$ & $0.76(0.41,1.39)$ \\
\hline Class 3 (increasing) & $0.66(0.31,1.42)$ & $0.71(0.38,1.33)$ & $0.80(0.32,1.97)$ \\
\hline Class 4 (high-stable) & $1.68(0.75,3.80)$ & $4.65(1.95,11.1)$ & $6.59(2.69,16.1)$ \\
\hline \multicolumn{4}{|l|}{ Fully adjusted models ${ }^{c}$} \\
\hline Class 1 (low-stable) & $1.31(0.95,1.79)$ & $1.31(0.98,1.75)$ & $1.26(0.77,2.05)$ \\
\hline Class 2 (moderate-stable) & $1.45(0.69,2.27)$ & $1.11(0.74,1.67)$ & $0.72(0.39,1.33)$ \\
\hline Class 3 (increasing) & $0.66(0.31,1.40)$ & $0.69(0.37,1.29)$ & $0.78(0.32,1.86)$ \\
\hline Class 4 (high-stable) & $1.73(0.78,3.86)$ & $4.66(1.98,10.9)$ & $6.51(2.77,15.3)$ \\
\hline
\end{tabular}

${ }^{a}$ Ignoring incident DM during follow-up

${ }^{\mathrm{b}}$ Excluding patients with prevalent DM at baseline

c Adjusted for age, sex, education, smoking status, BMI, and physical activity

therapy and patients without diabetes but a prior myocardial infarction carry the same cardiovascular risk [18]. In addition, depression in CHD patients leads to lower adherence to oral hypoglycemic, antihypertensive, and lipid-lowering medication and unfavorable lifestyle choices $[19,20]$. Therefore, it is not surprising that patients with a previous CVE and DM are at especially high risk for a subsequent $C V E$. 
In this cohort of patients with CHD, we previously observed an increased risk for subsequent CVE in patients following a high-stable depression symptoms trajectory [13]. A finding now substantiated by the observation that also the risk for incident DM is increased, which subsequently increases the risk for CVE massively.

\section{Possible pathogenic mechanism linking depression, diabetes, and CHD}

Solid evidence accumulates that depression is a risk factor for DM, irrespective of measures used to evaluate it, as seen in a recent meta-analysis [21]. Recent results of the Maastricht study indicate hyperglycemia itself may be involved in the etiology of depression [22]. In that study, several indicators of hyperglycemia (fasting plasma glucose, two-hour post-load glucose, and HbA1c) were consistently associated with a higher risk of incident depression independent of lifestyle factors. In addition, diabetes-associated microvascular dysfunction may be associated with the risk of incident depression [23].

$\mathrm{DM}$ is associated with chronic low-grade inflammation [24], as is depression [25-28]. Also, anti-cytokine treatments exhibit antidepressant effects in chronic inflammatory conditions [29], pointing to a causal role of chronic inflammation in the etiology of depression. Besides nonmodifiable risk factors such as ethnicity, family history, and older age, the following modifiable risk factors play a role in DM etiology: obesity, physical inactivity, smoking, and unhealthy diet [30]. Especially obesity, but also physical inactivity and smoking may result in changes in inflammatory status. In obesity, dyslipidemia and changes in circulating leptin serum values may also be present. In a recent study from Augsburg, Germany, investigating the relevance of biomarker-defined pathways for the development of DM, and also for coronary heart disease, many associations, such as cytokines, endothelial dysfunction, hemostasis, hormone regulation, tissue remodeling, and others, showed similar strength for DM and $\mathrm{CHD}$, but the insulin-like growth factor binding protein 2 explained DM risk best [10]. Interestingly, the risk associated with $\mathrm{N}$-terminal prohormone of brain natriuretic peptide (NT-proBNP) for DM was inverse, whereas it was positive for $\mathrm{CHD}$. This finding was substantiated in a subsequent analysis. High plasma concentrations of midregional pro atrial natriuretic peptide (MR-proANP), another peptide from the natriuretic peptide system, were also associated with a lower risk of incident DM and insulin resistance [31].

An earlier analysis of our data suggested that wellestablished risk factors like BMI, physical activity, or lowgrade chronic inflammation might be associated with categories of symptoms of depression [32]. An inverse association between physical activity and depression symptoms was also described in the British Whitehall II study [33]. Physical activity is also clearly in associated with reduced risk of incident DM [34]. In our current analysis, the associations of depression symptom trajectories with incident DM were slightly attenuated by adjusting for baseline lifestyle factors (including BMI and physical activity).

Patients with depression seem to have an increased autonomic nervous system activity, increased hypothalamic-pituitary-adrenocortical axis (HPA) activity and associated cardiovascular adverse effects, including vasoconstriction, increased heart rate, and heart rate variability $[4,35]$. Therefore, the increased activity of the HPA and the dysregulation of the immune system are discussed as risk factors for DM but may also play an important role in subsequent cardiovascular adverse effects.

\section{Strengths and limitations}

As the study population is predominantly male, we cannot be sure that all findings equally apply to women as well. Furthermore, the study population was recruited about three weeks after the initial acute event and only included patients referred and willing to participate in an in-patient cardiac rehabilitation. Although cardiac rehabilitation is the standard treatment of CHD in Germany, not all patients participate in the program, which could lead to an underrepresentation of severely ill patients. However, in Germany, in general, over $80 \%$ of patients participated in cardiac rehabilitation after myocardial infarction at the time of baseline recruitment of this study [36]. In addition, a recent analysis of electronic medical records from the US, including patients with ischemic heart disease, showed that the presence of comorbid depression was associated with greater participation in cardiac rehabilitation [37]. While our analyses do not allow a causal interpretation, depression symptoms in CHD patients may still be used as risk markers for DM and an increased risk for subsequent CVE.

\section{Clinical implications}

There is a need to decrease DM risk in patients with $\mathrm{CHD}$, especially as those who have both diseases have a two- to six-fold increased risk for cardiovascular death [30]. As the HADS is basically a screening instrument, further psychiatric referrals or clinical assessments are still needed to confirm the diagnosis. If the diagnosis is corroborated, a cardiac rehabilitation program should include psychological and physical activity interventions. A comprehensive cardiac rehabilitation program including diet, physical activity, and stress management reduced cardiovascular mortality, non-fatal myocardial infarction, and stroke by $33 \%$ at 3 years [38]. In addition, a meta-analysis of six types of interventions in CHD 
patients found that psychological and behavioral interventions reduced depression scores, all-cause mortality, and incidence of non-fatal myocardial infarction [39]. While cardiac rehabilitation programs with psychological and physical activity interventions effectively reduce depression symptoms and improve prognosis [38, 39], the implementation of these interventions in cardiac rehabilitation programs needs further evaluation.

\section{Conclusions}

In patients with $\mathrm{CHD}$, following a trajectory of high stable symptoms of depression was associated with an increased risk of incident DM. Furthermore, incident DM in these patients was associated with a substantially increased risk of subsequent CVE. Identifying depressive symptoms and pertinent treatment offers might be an important and promising approach to enhance outcomes in patients with CHD, which should be followed up in further research and practice.

\section{Abbreviations}

BMI: Body mass index; CHD: Coronary heart disease; Cl: Confidence interval; CRP: C-reactive protein; CVE: Cardiovascular event; DM: Diabetes mellitu; HADS: Hospital anxiety and depression scale; HR: Hazard ratio; ICD: International Classification of Diseases; MR-proANP: Mid-regional pro atrial natriuretic peptide; NT-proBNP: N-terminal prohormone of brain natriuretic peptide.

\section{Acknowledgements}

Not applicable.

\section{Authors' contributions}

RSP, DR and HB conceived the study. RSP performed the statistical analysis. UM, BS, RS, WK and HB participated in the design and conduct, and coordination of the study. RSP, UM, BS, RS, WK, HB and DR have been involved in drafting the manuscript or revising it critically for important intellectual content. All authors read and approved the final manuscript.

\section{Funding}

Open Access funding enabled and organized by Projekt DEAL. This work was supported by the Bundesministerium für Bildung und Forschung (grant \#01GD9820/0), the Pitzer Foundation (Bad Nauheim, Germany), and the Waldburg-Zeil Clinics (Isny, Germany)

\section{Availability of data and materials}

The datasets used and/or analysed during the current study are available from the corresponding author on reasonable request.

\section{Declarations}

\section{Ethics approval and consent to participate}

All subjects gave written informed consent. The study was approved by the Ethics Boards of the Universities of UIm (No.186/98) and Heidelberg and the Physicians' chambers of the States of Baden-Württemberg and Hessen.

\section{Consent for publication}

Not applicable.

\section{Competing interests}

Dr. Koenig reports personal fees from AstraZeneca, Novartis, Pfizer, The Medicines Company, DalCor, Kowa, Amgen, Corvidia, Daiichi-Sankyo, BerlinChemie, Genentech, OMEICOS, Esperion, Sanofi, Novo Nordisk, Bristol-Myers
Squibb, grants and non-financial support from Beckmann, Singulex, Abbott, and Roche Diagnostics, outside the submitted work.

\section{Author details}

${ }^{1}$ Institute of Epidemiology and Medical Biometry, Ulm University, Ulm, Germany. ${ }^{2}$ Division of Clinical Epidemiology and Ageing Research, German Cancer Research Center (DKFZ), Heidelberg, Germany. ${ }^{3}$ Faculty of Medicine and University Hospital Cologne, Heart Center, University of Cologne, Cologne, Germany. ${ }^{4}$ Network Ageing Research, University of Heidelberg, Heidelberg, Germany. ${ }^{5}$ Klinik Schwabenland, Isny-Neutrauchburg, Germany. ${ }^{6}$ Deutsches Herzzentrum München, Technische Universität München, Munich, Germany. ${ }^{7}$ German Centre for Cardiovascular Research (DZHK), Partner Site Munich Heart Alliance, Munich, Germany.

Received: 23 February 2021 Accepted: 5 May 2021

Published online: 13 May 2021

\section{References}

1. Khan MAB, Hashim MJ, King JK, Govender RD, Mustafa H, Al Kaabi J. Epidemiology of type 2 diabetes — Global burden of disease and forecasted trends. J Epidemiol Glob Health. 2020;10:107-11.

2. Mezuk B, Eaton WW, Albrecht S, Golden SH. Depression and type 2 diabetes over the lifespan: a meta-analysis. Diabetes Care. 2008;31:2383-90.

3. Nouwen A, Winkley K, Twisk J, Lloyd CE, Peyrot M, Ismail K, et al. Type 2 diabetes mellitus as a risk factor for the onset of depression: a systematic review and meta-analysis. Diabetologia. 2010;53:2480-6.

4. Knol MJ, Twisk JWR, Beekman ATF, Heine RJ, Snoek FJ, Pouwer F. Depression as a risk factor for the onset of type 2 diabetes mellitus. A metaanalysis. Diabetologia. 2006:49:837-45.

5. de Groot M, Anderson R, Freedland KE, Clouse RE, Lustman PJ. Association of depression and diabetes complications: a meta-analysis. Psychosom Med. 2001;63:619-30.

6. Lin EHB, Rutter CM, Katon W, Heckbert SR, Ciechanowski P, Oliver MM, et al. Depression and advanced complications of diabetes: a prospective cohort study. Diabetes Care. 2010;33:264-9.

7. Inoue K, Beekley J, Goto A, Jeon CY, Ritz BR. Depression and cardiovascular disease events among patients with type 2 diabetes: a systematic review and meta-analysis with bias analysis. J Diabetes Complications. 2020;34:107710.

8. Bauer AM, Parker MM, Moffet HH, Schillinger D, Adler NE, Adams AS, et al. Depressive symptoms and adherence to cardiometabolic therapies across phases of treatment among adults with diabetes: the Diabetes Study of Northern California (DISTANCE). Patient Prefer Adherence. 2017:11:643-52.

9. WHO. WHO reveals. leading causes of death and disability worldwide: 2000-2019. 2020 (cited 2021 Jan 28). https://www.who.int/news/item/ 09-12-2020-who-reveals-leading-causes-of-death-and-disability-world wide-2000-2019.

10. Huth C, Bauer A, Zierer A, Sudduth-Klinger J, Meisinger C, Roden M, et al. Biomarker-defined pathways for incident type 2 diabetes and coronary heart disease-a comparison in the MONICA/KORA study. CardiovasC Diabetol. 2020;19:32.

11. Lawler PR, Bhatt DL, Godoy LC, Lüscher TF, Bonow RO, Verma S, et al. Targeting cardiovascular inflammation: next steps in clinical translation. Eur Heart J. 2021:42:113-31.

12. Dantzer R, O'Connor JC, Freund GG, Johnson RW, Kelley KW. From inflammation to sickness and depression: when the immune system subjugates the brain. Nat Rev Neurosci. 2008;9:46-56.

13. Peter RS, Meyer ML, Mons U, Schöttker B, Keller F, Schmucker R, et al. Long-term trajectories of anxiety and depression in patients with stable coronary heart disease and risk of subsequent cardiovascular events. Depress Anxiety. 2020;37:784-92.

14. Rothenbacher D, Hahmann H, Wüsten B, Koenig W, Brenner H. Symptoms of anxiety and depression in patients with stable coronary heart disease: prognostic value and consideration of pathogenetic links. European Journal of Cardiovasc Prev \& Rehabil. 2007;14:547-54.

15. Herrmann C. International experiences with the hospital anxiety and depression scale-a review of validation data and clinical results. J Psychosom Res. 1997;42:17-41. 
16. Zigmond AS, Snaith RP. The hospital anxiety and depression scale. Acta Psychiatr Scand. 1983;67:361-70.

17. Hasan SS, Clavarino AM, Mamun AA, KairuzT. Incidence and risk of diabetes mellitus associated with depressive symptoms in adults: evidence from longitudinal studies. Diabetes Metab Syndr. 2014;8:82-7.

18. Schramm TK, Gislason GH, Køber L, Rasmussen S, Rasmussen JN, Abildstrøm SZ, et al. Diabetes patients requiring glucose-lowering therapy and nondiabetics with a prior myocardial infarction carry the same cardiovascular risk: a population study of 3.3 million people. Circulation. 2008; 117:1945-54.

19. Lin EHB, Katon W, Korff MV, Rutter C, Simon GE, Oliver M, et al. Relationship of depression and diabetes self-care, medication adherence, and preventive care. Diabetes Care Am Diabetes Assoc. 2004;27:2154-60.

20. Sharif S, Raza MT, Mushtaq S, Afreen B, Hashmi BA, Ali MH. Frequency of depression in patients with type 2 diabetes mellitus and its relationship with glycemic control and diabetic microvascular complications. Cureus. 2019;11:e5145.

21. Graham EA, Deschênes SS, Khalil MN, Danna S, Filion KB, Schmitz N. Measures of depression and risk of type 2 diabetes: a systematic review and meta-analysis. J Affect Disord. 2020;265:224-32.

22. Geraets AFJ, Köhler S, Muzambi R, Schalkwijk CG, Oenema A, Eussen SJPM, et al. The association of hyperglycaemia and insulin resistance with incident depressive symptoms over 4 years of follow-up: the Maastricht Study. Diabetologia. 2020;63:2315-28.

23. van Agtmaal MJM, Houben AJHM, Pouwer F, Stehouwer CDA, Schram MT. Association of microvascular dysfunction with late-life depression: a systematic review and meta-analysis. JAMA Psychiatry. 2017;74:729-39.

24. Wang $X, B a o$ W, Liu J, Ouyang Y-Y, Wang D, Rong S, et al. Inflammatory markers and risk of type 2 diabetes: a systematic review and meta-analysis. Diabetes Care. 2013;36:166-75.

25. Howren MB, Lamkin DM, Suls J. Associations of depression with C-reactive protein, IL-1, and IL-6: a meta-analysis. Psychosom Med. 2009;71:171-86.

26. Milaneschi Y, Corsi AM, Penninx BW, Bandinelli S, Guralnik JM, Ferrucci $L$. Interleukin-1 receptor antagonist and incident depressive symptoms over 6 years in older persons: the InCHIANTI study. Biol Psychiatry. 2009:65:973-8.

27. Tayefi M, Shafiee M, Kazemi-Bajestani SMR, Esmaeili H, Darroudi S, Khakpouri S, et al. Depression and anxiety both associate with serum level of hs-CRP: a gender-stratified analysis in a population-based study. Psychoneuroendocrinology. 2017:81:63-9.

28. Roohi $\mathrm{E}$, Jaafari N, Hashemian F. On inflammatory hypothesis of depression: what is the role of IL-6 in the middle of the chaos? J Neuroinflammation. 2021;18:45.
29. Kappelmann N, Lewis G, Dantzer R, Jones PB, Khandaker GM. Antidepressant activity of anti-cytokine treatment: a systematic review and meta-analysis of clinical trials of chronic inflammatory conditions. Mol Psychiatry. 2018;23:335-43.

30. Glovaci D, Fan W, Wong ND. Epidemiology of diabetes mellitus and cardiovascular disease. Curr Cardiol Rep. 2019;21:21.

31. Sujana C, Seissler J, Jordan J, Rathmann W, Koenig W, Roden M, et al. Associations of cardiac stress biomarkers with incident type 2 diabetes and changes in glucose metabolism: KORA F4/FF4 study. Cardiovasc Diabetol. 2020;19:178.

32. Rothenbacher D, Jaensch A, Mons U, Hahmann H, Becker T, Koenig W, et al. Prognostic value of one-year course of symptoms of anxiety and depression in patients with coronary heart disease: Role of physical activity and unmet medical need. Eur J Prev Cardiol. 2015;22:1 129-38.

33. Azevedo Da Silva M, Singh-Manoux A, Brunner EJ, Kaffashian S, Shipley MJ, Kivimäki M, et al. Bidirectional association between physical activity and symptoms of anxiety and depression: the Whitehall II study. Eur J Epidemiol. 2012;27:537-46.

34. Aune D, Norat T, Leitzmann M, Tonstad S, Vatten LJ. Physical activity and the risk of type 2 diabetes: a systematic review and dose-response metaanalysis. Eur J Epidemiol. 2015;30:529-42.

35. Dhar AK, Barton DA. Depression and the link with cardiovascular disease. Front Psychiatry. 2016;7:33.

36. Grande G, Leppin A, Romppel M, Altenhöner T, Mannebach H. Women and men after acute myocardial infarction: are there gender differences in participation rates in cardiac rehabilitation? Rehabilitation (Stuttg). 2002:41:320-8.

37. Krishnamurthi N, Schopfer DW, Shen H, Whooley MA. Association of mental health conditions with participation in cardiac rehabilitation. J Am Heart Assoc. 2019;8:e011639.

38. Giannuzzi P, Temporelli PL, Marchioli R, Maggioni AP, Balestroni G, Ceci V, et al. Global secondary prevention strategies to limit event recurrence after myocardial infarction: results of the GOSPEL study, a multicenter, randomized controlled trial from the Italian Cardiac Rehabilitation Network. Arch Intern Med. 2008;168:2194-204.

39. Welton NJ, Caldwell DM, Adamopoulos E, Vedhara K. Mixed treatment comparison meta-analysis of complex interventions: psychological interventions in coronary heart disease. Am J Epidemiol. 2009;169:1158-65.

\section{Publisher's Note}

Springer Nature remains neutral with regard to jurisdictional claims in published maps and institutional affiliations.
Ready to submit your research? Choose BMC and benefit from:

- fast, convenient online submission

- thorough peer review by experienced researchers in your field

- rapid publication on acceptance

- support for research data, including large and complex data types

- gold Open Access which fosters wider collaboration and increased citations

- maximum visibility for your research: over $100 \mathrm{M}$ website views per year

At BMC, research is always in progress.

Learn more biomedcentral.com/submissions 